\title{
One-Dimensional Transient Analysis of Rainfall Infiltration in Unsaturated Volcanic Ash
}

\author{
James Fern, John Eichenberger, Alessio Ferrari, and Lyesse Laloui \\ Laboratory of Soil Mechanics, \\ School of Architecture, Civil and Environmental Engineering, \\ École Polytechnique Fédérale de Lausanne, \\ Station 18, 1015 Lausanne, Switzerland \\ \{james.fern, john.eichenberger\}@a3.epfl.ch, \\ \{alessio.ferrari, lyesse.laloui\}@epfl.ch \\ http://lms.epfl.ch
}

\begin{abstract}
The paper presents a one-dimensional hydro-mechanical analysis of rainfall infiltration in a loose volcanic ash and the utilisation of a factor of safety for the implementation of an early-warning system. Three different rainy seasons with different rainfall patterns were analysed . The analysis aims to understand the influence of the antecedent rainfall on the wetting front, the pore-water pressures and the factor of safety. The analysis was carried out in the context of a Master project of the first author at the Laboratory for Soil Mechanics of EPFL.
\end{abstract}

Keywords: groundwater seepage, unsaturated volcanic ash, rainfallinduced landslide, infinity slope analysis.

\section{Introduction}

A shallow rainfall-induced landslide was triggered on $21^{\text {st }}$ November 2005 on the steep slopes of Irazù Volcano, Costa Rica. Three weeks later a second slide took place. The slides did not cause any casualties or extensive damage to property but lead to huge indirect costs due to the lose of productivity of local farmers and industries. Protection measures were already put into place in order to mitigate the risk but turned out to be ineffective [1].

The two slides were located in a thin layer of volcanic ash resting on a layer of clay in some places and or pozzolan in others. The volcanic ash was subjected to seasonal rainfall. The region has a long dry season followed by a short rainy season. Furthermore, this region is subjected to cyclic variation cause by El Niño. The study aims to analyse the influence of the different rainfall patterns on the predisposition of the slope to fail. The analysis is carried out by means of finite element simulation and infinite slope analysis. The simulation considered the field measurements of rainfall of three different years with three very different rainfall patterns. 


\section{Material Description}

The volcanic ash is a cohesionless poorly graded sand of USCS type SC-SM. It is composed of $48 \%$ of sand and $50 \%$ of silt. The grain-size distribution is shown in figure 1. It has an internal friction angle of $35.5^{\circ}$ and a specific gravity of 2.61. The ash is in a very loose state and has a density of $10 \mathrm{kN} / \mathrm{m}^{3}$. It was deposited by air-fall during the 1963-65 eruption. This deposition mechanism gave a grading to the deposited material. Boulders are located to the crater and the ashes further on the hillslopes. The USGS [1] reports a large accumulation of ash on the upper part of Irazù volcano despite its proximity to the crater.

A testing programme was set up to investigate the hydro-mechanical behaviour of the ash [2]. The soil water retention curve (SWRC) was obtained with a controlled-suction pressure plate apparatus and no hydric hysteresis was observed. Similar properties were observed on volcanic ash from Italy 4 . The SWRC was fitted with a van Genuchten model [5] and is shown in Fig. 1. The model parameters are summarized in table 1 .

$$
S_{w}=S_{w, r e s}+\left(1-S_{w, r e s}\right)\left[\frac{1}{1+(\alpha s)^{n}}\right]^{m}
$$

where $S_{w}$ is the degree of saturation, $S_{w, \text { res }}$ the residual degree of saturation, $s$ the matric suction and $\alpha, n$ and $m$ the van Genuchten model parameters.

Table 1. The van Genucthen parameters for the volcanic ash

\begin{tabular}{ccccc}
\hline$S_{w, r e s}$ & $s_{e}$ & $n$ & $m$ & $n$ \\
\hline $3 \%$ & $2 \mathrm{kPa}$ & 2.19 & 0.42 & 0.97 \\
\hline
\end{tabular}
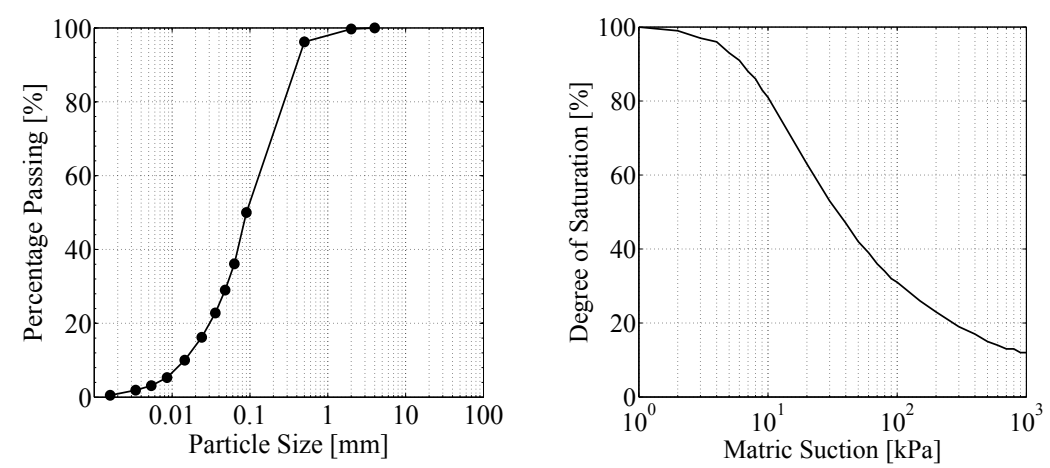

Fig. 1. Grain-size distribution and soil water retention curve 
The permeability law was derived from the SWRC as suggested in [5] and shown in Eq. 22 It is a cubic law expressed with the same parameters as the van Genuchten SWRC. The saturated permeability is reported to be $6.4 \cdot 10^{-6} \mathrm{~m} / \mathrm{s}$.

$$
k(s)=\frac{1-\left(\alpha \frac{s}{\gamma_{w}}\right)^{n-3}\left[1+\left(\alpha \frac{s}{\gamma_{w}}\right)^{n}\right]^{-m}}{\left[1+\left(\alpha \frac{s}{\gamma_{w}}\right)^{n}\right]^{2 m}}
$$

where $k$ is the unit permeability and $\gamma_{w}$ the unit weight of water.

\section{Constitutive Model}

The material was modelled with the 'Advanced Constitutive Model for Environmental Geomechanics' for unsaturated soil ACMEG-s [ 6 . It is a critical state model based set within the generalised effective stress framework 8 and uses Bishop's effective stress [7] with the coupling parameter equal to the degree of saturation 9 . (Eq. 3). The main advantages of such a framework are that any change in effective stress result in changes in strain and a smooth transition between saturated and unsaturated conditions.

$$
\sigma_{i j}^{\prime}=\sigma_{i j}^{n e t}+S_{w} s \cdot \delta_{i j}
$$

where $\sigma_{i j}^{\prime}$ is the effective stress, $\sigma_{i j}^{n e t}$ the net stress and $\delta_{i j}$ the Kronecker delta.

ACMEG-s considers two yielding mechanisms (volumetric and deviatoric) and its yield surface is defined by two yield equations (Eq. 5and4). Despite a double yield function, only a single yield surface exists at any given time (Fig. (2).

$$
\begin{gathered}
f_{\text {iso }}=p^{\prime}-p_{c}^{\prime} \cdot r_{i s o} \\
f_{d e v}=q-M p^{\prime}\left[1-b \cdot \log \left(\frac{d \cdot p^{\prime}}{p^{\prime} c}\right)\right] \cdot r_{d e v}
\end{gathered}
$$

where $p_{c}^{\prime}$ is the preconsolidation, $d$ and $b$ material parameters and $r_{i s o}$ and $r_{d e v}$ the deviatoric and isotropic mobilisation factors.

ACMEG-s has a non-associative flow rule for the deviatoric mechanism and an associative for the volumetric. It has a standard Cambridge type flow rule (Eq. 6).

$$
\frac{d \varepsilon_{v}^{p}}{d \varepsilon_{d}^{p}}=\alpha \cdot\left(M-\frac{q}{p^{\prime}}\right)
$$

where $d \varepsilon_{v}^{p}$ and $d \varepsilon_{d}^{p}$ are respectively the plastic volumetric and deviatoric strain increments, $\alpha$ the dilatancy coefficient, $M$ the critical state stress ratios.

ACMEG-s assumes a volumetric strain driven hardening rule (Eq. 7) in which the compressibility coefficient $\beta$ is a function of the matric suction (Eq. 8 ).

$$
p_{c}^{\prime}=p_{c 0}^{\prime} \cdot \exp \left(\beta \varepsilon_{v}^{p}\right)
$$




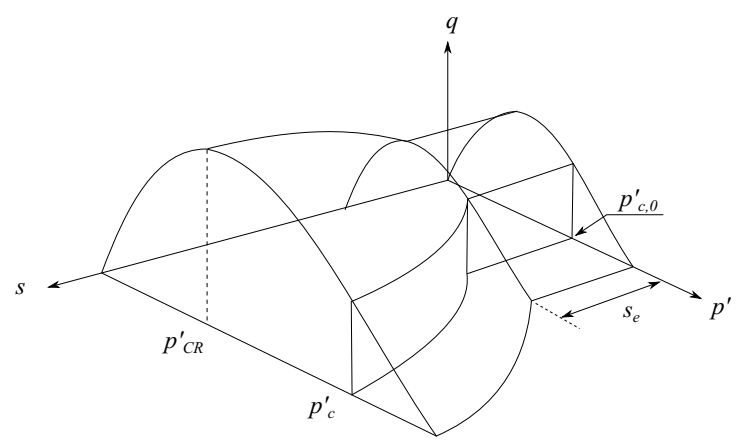

Fig. 2. ACMEG-s yield surface

$$
\beta=\beta_{0}+\Omega s
$$

where $p_{c 0}$ and $p_{c}^{\prime}$ are respectively the saturated and unsaturated preconsolidation pressures, $\beta_{0}$ the saturated compressibility coefficient and $\Omega$ its unsaturated enhancement coefficient.

The evolution of the preconsolidation pressure is defined by the loadingcollapse curve (LC) and shown in Eq. 9 and 10.

$$
\begin{array}{ll}
p_{c}^{\prime}=p_{c, 0}^{\prime}\left[1+\gamma_{s} \cdot \ln \left(\frac{s}{s_{e}}\right)\right] & \text { for } s \geq s_{e} \\
p_{c}=p_{c, 0}^{\prime} & \text { for } s<s_{e}
\end{array}
$$

where $\gamma_{s}$ are material parameters and $s_{e}$ the air-entry suction value.

Table 2. ACMEG-s parameters

\begin{tabular}{lll}
\hline Bulk modulus & $K_{\text {ref }}$ & $2.0 \cdot 10^{4} \mathrm{kPa}$ \\
\hline Shear modulus & $G_{r e f}$ & $1.5 \cdot 10^{4} \mathrm{kPa}$ \\
\hline Elastic exponent & $n$ & 0.5 \\
\hline Friction angle & $\phi^{\prime}$ & $35.5^{\circ}$ \\
\hline Compressibility Coefficient & $\beta_{0}$ & 9 \\
\hline Dilatancy coefficient & $a l p h a$ & 0.8 \\
\hline Material parameter & $a$ & 0.08 \\
\hline Material parameter & $b$ & 0.01 \\
\hline Material parameter & $c$ & 0.08 \\
\hline Material parameter & $d$ & 2 \\
\hline Initialisation of dev. mech. & $r_{\text {dev }}$ & 0.2 \\
\hline Initialisation of iso. mech. & $r_{i s o}$ & 0.3 \\
\hline LC-curve coefficient & $\gamma_{s}$ & 1.6 \\
\hline Compressibility enhancement coefficient $\Omega$ & 0 \\
\hline
\end{tabular}


The choice of the constitutive model was motivated by its ability of modelling to model cohesionless material 10. The model parameters were obtained from an experimental programme consisting in three suction-controlled oedometer tests and three saturated triaxial compression tests 2. The initial conditions reflected the field observations - loose and at low stresses. The model parameters were derived from these tests and refined by curve-fitting using a single element Gauss point routine 11] and are shown in Table 2,

\section{One-Dimensional Transient Analysis of Rainfall Infiltration}

The aim of the numerical analysis is to investigate the influence of rainfall patterns on the predisposition of a slope to fail considering both space and time. Rainfall infiltration is a downward gravity-driven mechanism and may be analysed with a one dimensional description of the problem [12. A $6 \mathrm{~m}$ deep and $1 \mathrm{~m}$ wide ash-filled column is modelled using the finite element programme LAGAMINE 1314]. The geometry, mesh and boundary conditions are shown in Fig. 3. A groundwater table is placed at $4 \mathrm{~m}$ depth. The bottom surface of the column is has a free drainage boundary condition. The boundary conditions are applied to the surface to prevent water ponding. It aims to replicated the runoff. The steep slopes prevent any ponding and the run-off water is immediately evacuated by gravity. The sides of the column impervious. The initial conditions of the volcanic ash are chosen to replicate the field investigation. The ash has an initial void ratio of 1.6. In order to analysis the influence of the initial porewater pressure, each simulation is run twice with two different initial conditions. Both have hydrostatic profiles but the second has a cut-off value at $-20 \mathrm{kPa}$ of pore-water pressure. Fig. 3 illustrates these initial conditions.

The daily precipitation data was estimated by extrapolation from the daily precipitation of the International Airport of Santamaria located $36 \mathrm{~km}$ away. The data was obtained from the NOAA precipitation data base. Due to the unknown duration of each rainfall, the daily precipitation has been discretized throughout the day by applying a maximum intensity at midday and nil precipitation at midnight while conserving the daily precipitation volume. This discretization is conservative as it favours rainfall infiltration. However, The type of precipitation is neglected due to the shear size of the data (e.g. drizzle or storms). Furthermore, it is impossible to predict the local orographic effects in that region [1].

The transient pore-water pressure is obtained for each simulation and a factor of safety is calculated with the infinite slope theory (Eq. 111). It assumes a slip surface parallel to the ground surface and neglects the effect of neighbouring slopes. It takes into account the destabilising effect of weight, the stabilising effect of matric suction and the angle of the slope. The use of the this factor of safety for the implementation of an early-warning system is fully discussed in [11. A $49^{\circ}$ slope is used for all simulations.

$$
F S=\frac{c^{\prime}+\left(\gamma H \cos ^{2} \theta+S_{w} s\right)}{\gamma z \sin \theta \cos \theta}
$$


where $c^{\prime}$ is the intercept cohesion, $\phi^{\prime}$ the shear strength angle, $\gamma$ the unit weight of the soil, $z$ the depth of the point considered in the analysis, $\theta$ the angle of the slope surface.

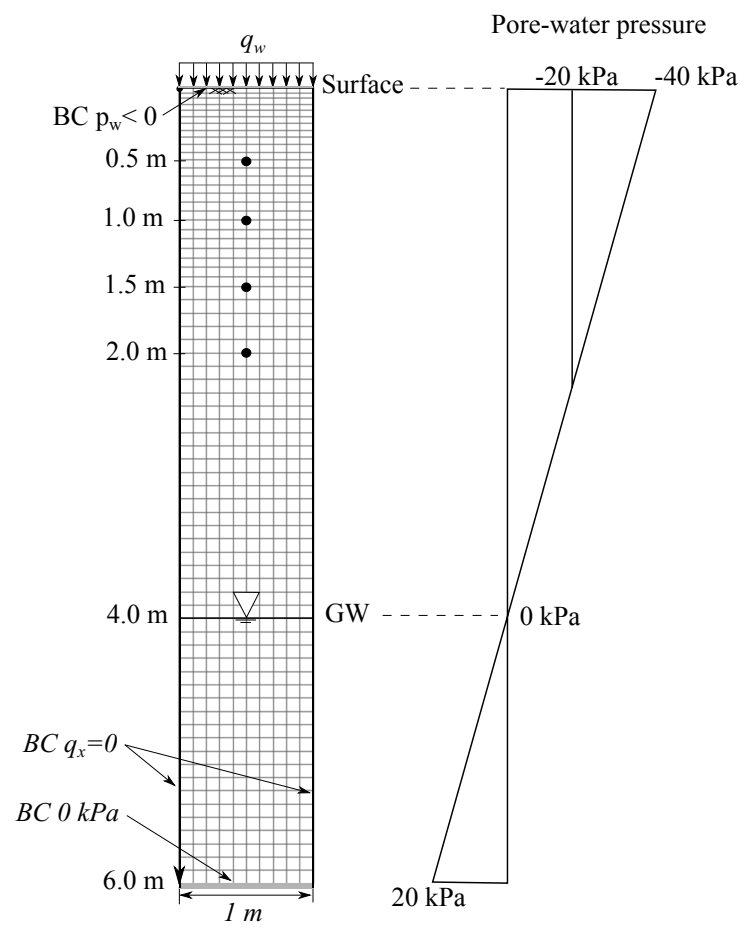

Fig. 3. Geometry, mesh, boundary and initial conditions of the one dimensional analysis

The ash filled column replicates the infiltration process of a $49^{\circ}$ slope. The simulation were run as fully coupled meaning that wetting-induced strain was permitted. Four depth are analysed $(0.5,1.0,1.5$ and $2.0 \mathrm{~m})$ and shown in Fig. 4. 5 and 6. The term duration refers to the number of days with some rainfall rather than the actual duration of a rainfall event.

\subsection{Rainy Season}

The rainy season of year 2005 is simulated using the rainfall pattern shown in Fig. 4h. The cumulative rainfall is $1200 \mathrm{~mm}$ and most of it occurred in September and October. Very few days in these two month did not have any rain and the maximum daily precipitation was $56 \mathrm{~mm} /$ day. The matric suction and the factor

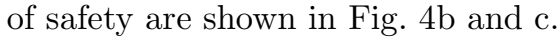



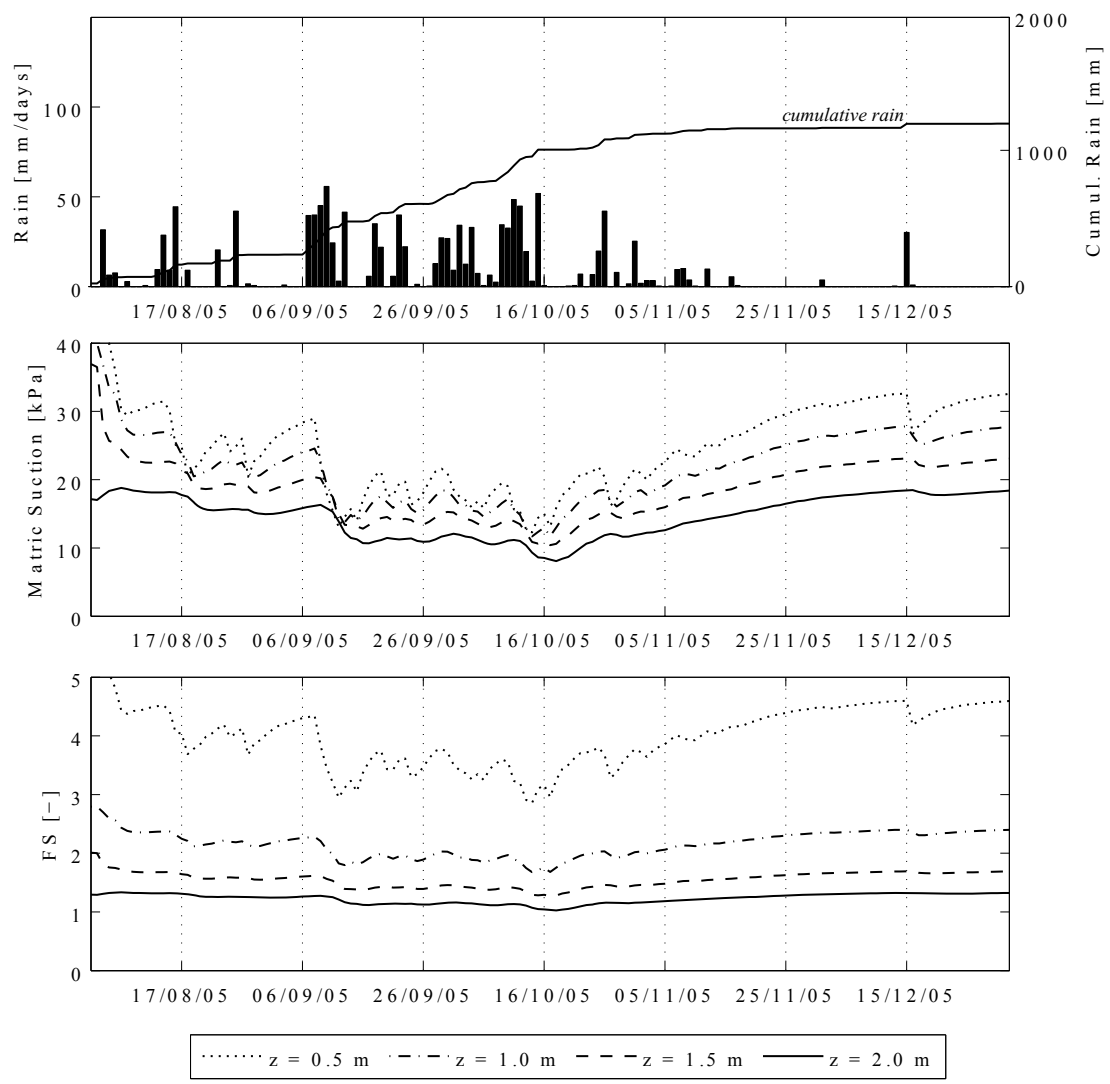

Fig. 4. Rainfall, pore-water pressure and factor of safety for the rainy season 2005

The first few days are subjected to small intensity long duration rainfalls which rule out any influence of the initial conditions after twenty days. The matric suction profiles in the ground are as from then the same. By the end of August, the matric suction is $15 \mathrm{kPa}$ at $2 \mathrm{~m}$ depth and $28 \mathrm{kPa}$ at $0.5 \mathrm{~m}$ depth and the factors of safety respectively 1.26 and 4.30 . The early September showers cause the matric suction and the factors of safety to drop and the rate of drop is more significant at shallow depths. The matric suctions are $13 \mathrm{kPa}$ at all depth while the factor of safety is graded from 2.95 at $0.5 \mathrm{~m}$ to 1.16 at $2 \mathrm{~m}$. For the following month, the rainfalls are uniform in intensity and duration. A series of high intensity and long duration rainfalls occurs mid-October and is similar to one in September. The matric suctions drop down to $8 \mathrm{kPa}$ at $2 \mathrm{~m}$ deep with a factor of safety of 1.03. This date corresponds to the date of the actual landslide.

The 2005 results show that a single day of rainfall is not sufficient to affect the stability of the ground at $2 \mathrm{~m}$ depth. However, a series of rainfalls increases the degree of saturation and the permeability of the ground and decreases the 
matric suction. Then only can a high intensity rainfall decrease significantly the matric suction and give a critical factor of safety.

\subsection{Rainy Season}

The rainy season of year 2008 is simulated using the rainfall pattern shown in Fig. 5a. The cumulative rainfall was $1525 \mathrm{~mm}$ most of which occurred in August and September. Unlike 2005, the rainfall is composed of less events but with higher intensities. The maximum rainfall intensity is $133 \mathrm{~mm} /$ day. The matric suction and the factor of safety are shown in Fig. 5 b and c.
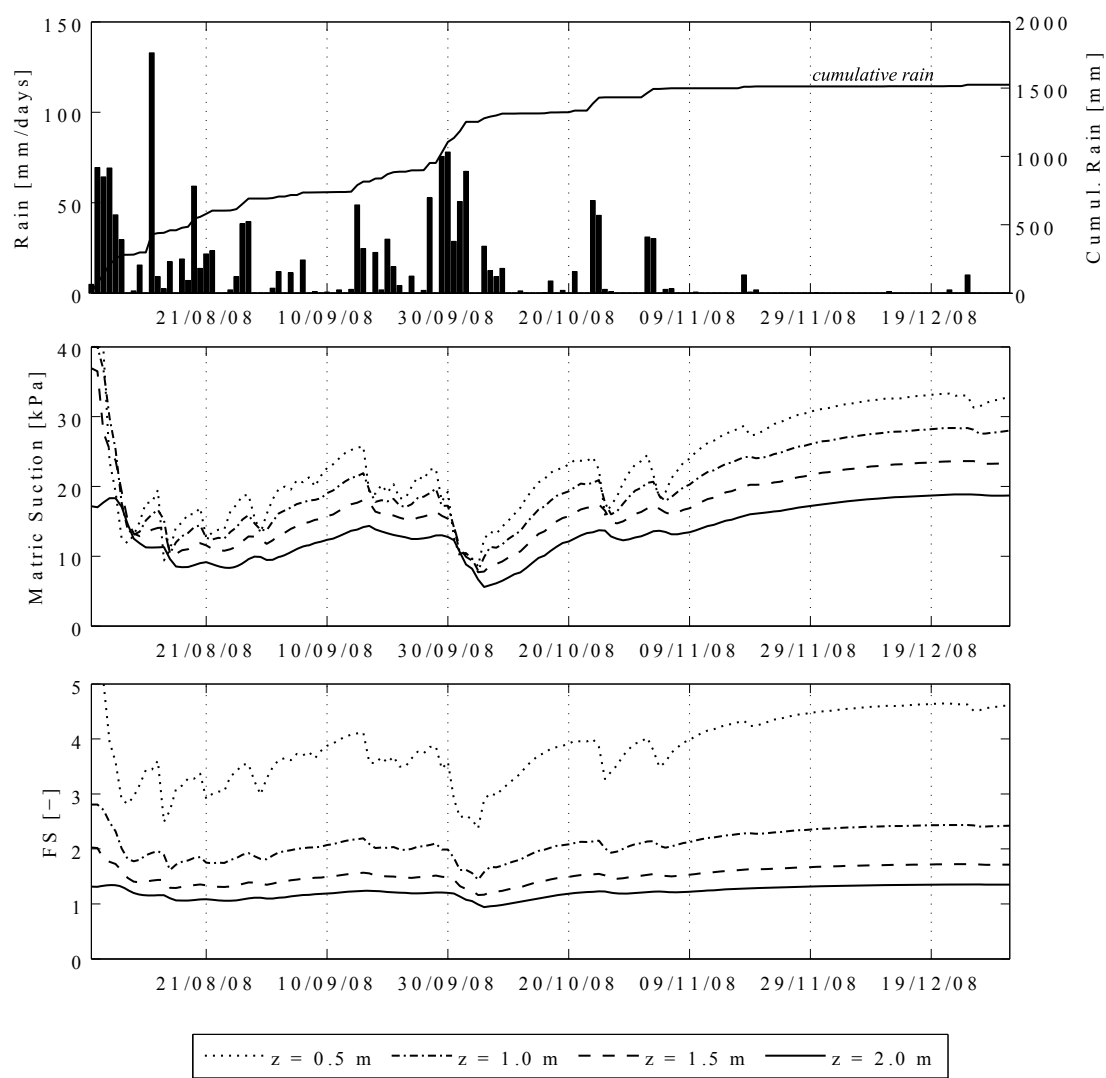

Fig. 5. Rainfall, pore-water pressure and factor of safety for the rainy season 2008

The early August rain remove any influence of the initial matric suction. By mid-August, the heavy rainfall infiltration have set the matric suction to $12 \mathrm{kPa}$ at all depths. The factor of safety at a depth of $2 \mathrm{~m}$ is 1.12 . Then, a single high intensity rainfall occurs. The shallow layers respond to it very quickly with a 
rapid decrease in matric suction to $9 \mathrm{kPa}$ while the $12 \mathrm{kPa}$ are maintained at 2 $\mathrm{m}$ depth. However, the factor of safety is still high. The following is rather dry and the soil is free to drain. Matric suction increases and stability is gained. A long duration and high intensity series of rainfall occur at the end of September. Despite the lower intensity, the consequence are dramatic. The matric suction is between 5 and $7 \mathrm{kPa}$ at all depth and the factor of safety is 0.94 . October and November are subject to sporadic showers which have an effect at shallow depths but none at $2 \mathrm{~m}$ depth.

The 2008 results show that single events mainly affect shallow depth unless the soil has been subjected to antecedent rainfall. The effect of heavy rainfall are limited by the permeability of the ground. The increase in permeability requires some time while which the water flow is unable to fully saturated the pore space giving a constant matric suction value to the entire profile.

\subsection{Rainy Season}

The rainy season of year 2010 is simulated using the rainfall pattern shown in Fig. 6a. The cumulative rainfall us $1557 \mathrm{~mm}$ and is similar to 2008. It is split into three major events. A small intensity but long lasting series of precipitation occurs in the month of August. It is followed by first high intensity rainfall event with an intensity of $128 \mathrm{mmm} /$ day. After two weeks of dry weather, a second high intensity event occurs with an intensity of $133 \mathrm{~mm} /$ day. The matric suction and the factor of safety are shown in Fig. $5 \mathrm{~b}$ and c.

The first six weeks are subjected to continuous rainfall and both the matric suction and the factor of safety gradually decrease to values of respectively 17 $\mathrm{kPa}$ and 3 at $0.5 \mathrm{~m}$ depth and $10 \mathrm{kPa}$ and 1.08 at $2 \mathrm{~m}$ depth. The total amount of rainfall is $603 \mathrm{~mm}$. It is followed by the first high intensity rainfall event and the matric rapidly drops down to $9 \mathrm{kPa}$ at all depth. The rate of decrease is more significant at shallow depths than at higher depths. The factor of safety reaches its minimum value of 2.1 at $0.5 \mathrm{~m}$ depth. A lag-time of two 2 days is required for the deeper soil to respond. It then has a matric suction of $4.5 \mathrm{kPa}$ and a factor of safety 0.9 at $2 \mathrm{~m}$. At the end of this first series of high intensity rainfalls occurs a few lower intensity events but nevertheless non-negligible. This additional water is channelled into the soil because of the high permeability and finally reaches the deeper soil. The matric suction drops to $3 \mathrm{kPa}$ and the factor of safety to 0.82 . This event highlights the influence of the antecedent rainfall on the response of the soil to a single event. The following month is rather dry and the matric suction increases in the soil at all depths. The second series of high intensity rainfalls occurs mid-October. The matric suction profile is inversed with a matric suction of $4 \mathrm{kPa}$ at $0.5 \mathrm{~m}$ depth and $6 \mathrm{kPa}$ at $2 \mathrm{~m}$ meters time with a lag-time of 2 days. The factors of safety are respectively 1.51 and 0.97 . 

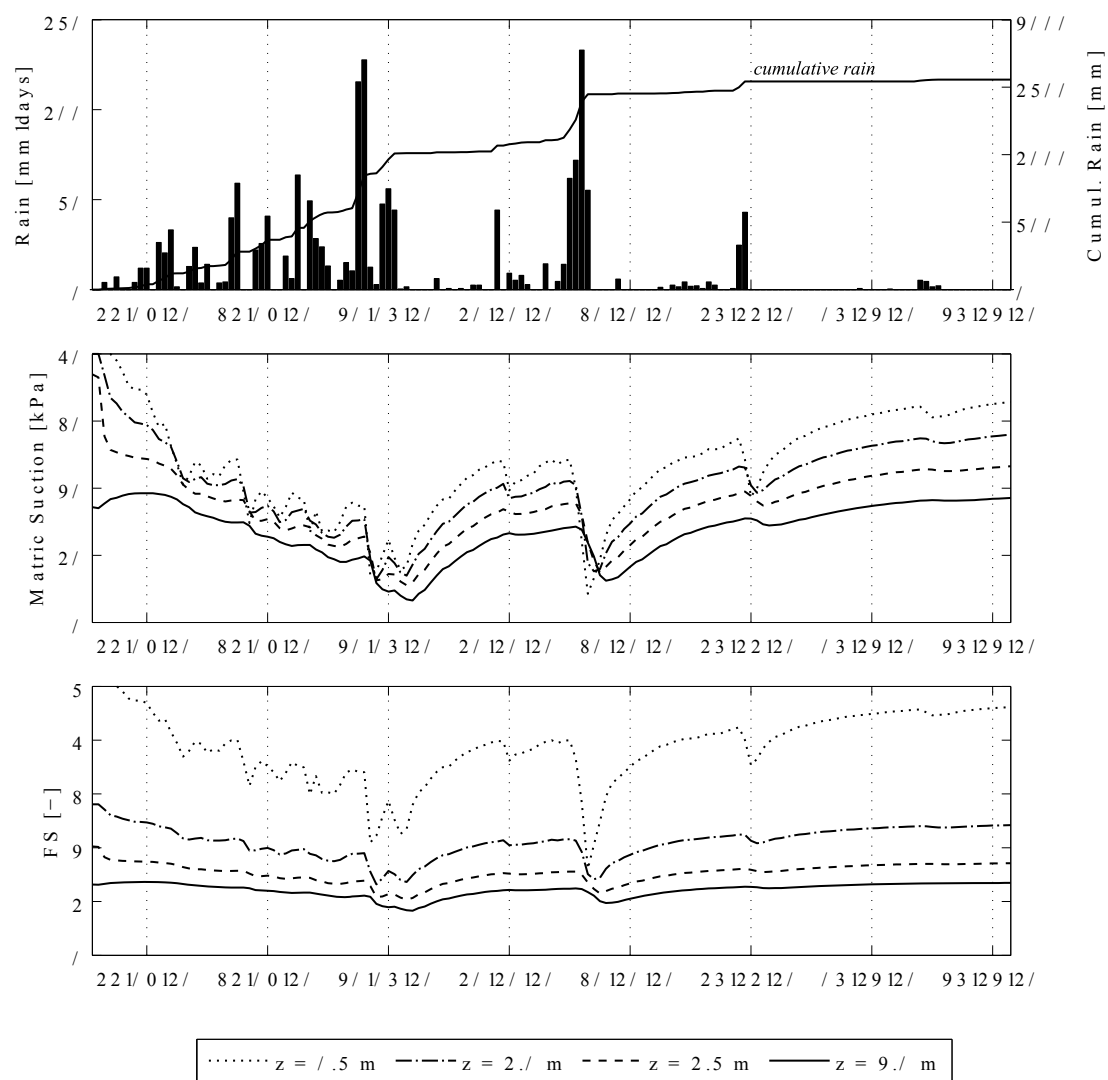

Fig. 6. Rainfall, pore-water pressure and factor of safety for the rainy season 2010

\section{Conclusion}

The one-dimensional modelling of rainfall infiltration is a suitable approach as long as no perched water tables are formed in the ground 12. These may be caused by a contrast in permeability between two materials or even within the same material. This simple models excludes any topographic or stratigraphic effects which may be in some cases significant [17/16]15. Nevertheless, this simple model allows to gain some insight on the hydraulic behaviour of soil subjected to rainfall.

The use of a factor of safety illustrates the predisposition of a soil to fail. It may be seen that deeper soil are less stable but are less sensitive to single events than shallow soils. The actual value of the factor of safety is subjected to some discussion as it relies on many assumptions (e.i. infinity slope analysis and the rainfall patterns). The analysis neglected any anthropogenic or seismic contributions. 
The finite element simulation of an ash filled column subjected to the 2005 rainy season rainfall predicted two landslides as observed in the field. However, the 2008 and 2010 simulation also predicted failures which di not occur. It may partly be explained by the estimation of the rainfall and its discretisation. Orographic effects may have also modified the precipitation both in time and in space. Anthropogenic activities or tectonic activity may have also played a role in the 2005 events. Nevertheless, the following conclusion may be drawn from the analysis.

1. Soil is sensitive at shallow depths to single events of rainfall but their predisposition to fail is rather small.

2. Rainfall infiltration increases the permeability allowing more water to penetrate into the ground forming a wetting front.

3. This wetting front is able to reach deeper strata and increases predisposition of soil to fail.

4. Deeper soil is only then sensitive to a single events of rainfall.

5. A lag-time of two days is observed between the rainfall event and the decrease in matric suction at deeper depths.

6. The lag-time means that the risk of a slide is at its most well after the rainfall events rather than during.

Acknowledgments. The authors would like to thank NOAA for sharing their precipitation data.

\section{References}

1. Waldron, H.H.: Debris Flow and Erosion Control Problems Caused by the Ash Eruptions of Irazu Volcano, Costa Rica. USGS Numbered Series - Contribution to genreal geology, vol. 1241, pp. 1-37 (1966)

2. Ferrari, A., Eicheberger, J., Laloui, L.: Hydromechanical Behaviour of a Volcanic Ash. Géotechnique, 1-14 (2013)

3. Ferrari, A., Eichenberger, J., Fern, J.: Experimental and Numerical Analysis of an Unsaturated Volcanic Ash Deposit for the Establishment of an Early Warning System in a Quarry in Costa Rica. In: Hryclw, R.D., Athanasopoulous-Zekkos, A. (eds.) GeoCongress ASCE 2012, pp. 2512-2521. American Society of Civil Engineers, Oakland (2012)

4. Bilotta, E., Cascini, L., Foresta, V., Sorbinow, G.: Geotechnical Characterisation of Pyroclastic Soils Involved in Huge Flow Slides. Geotechnical and Geological Engineering 23, 365-402 (2005)

5. Van Genuchten, M.T.: A Closed Form Equation for Predicting the Hydraulic Conductivity of Unsaturated Soils. Soil Science Society American Journal 44, 892-898 (1980)

6. Nuth, M.: Constitutive Modelling of Unsaturated Soils with Hydro-Geomechanical Couplings. École Polytechnique Fédérale de Lausanne (2009)

7. Bishop, A.W.: The principles of effective stress. Tecnisk Ukeblad 8, 859-863 (1959)

8. Nuth, M., Laloui, L.: Effective Stress Concept in Unsaturated Soils: Clarification and validation of a Unified Framework. International Journal for Numerical and Analytical Methods in Geomechanics 32, 771-801 (2008) 
9. Schrefler, B.: The Finite Element Method in Soil Consolidation (with applications to surface subsidence). University College of Swansea (1984)

10. D' Onza, F., Gallipoli, D., Wheeler, S.J.: Benchmark of Constitutive Models for Unsaturated Soils. G'eotechnique 61, 283-302 (2011)

11. Eichenberger, J.: Geomechanical Modelling of Rainfall-Induced Landslides in Partially Saturated Slopes. École Polytechnique Fédérale de Lausanne (2013)

12. Fredlund, D.G., Rahardjo, H.: Soil Mechanics for Unsaturated Soils. Wiley \& Sons, New York (1993)

13. Charlier, R.: Approche Unifiée de Quelques Problè mes non Linaires de Mcanique des Milieux Continus par la Méthode des éléments finis. Université de Liège (1987)

14. Collin, F.: Couplages Thermo-hydro-mćaniques dans les sols et les roches tendres partiellement saturés. Université de Liè ge (2003)

15. Eichenberger, J., Ferrari, A., Laloui, L.: Early Warning Thresholds for Partially Saturated Slopes in Volcanic Ashes. Computers and Geotechnics 49, 79-89 (2013)

16. Borja, R.I., White, J.A.: Continuum Deformation and Stability Analyses of a Steep Hillside Slope under Rainfall Infiltration. Acta Geotechnica 5, 1-14 (2010)

17. Pirone, M.: Analysis of Slope Failure Mechanism in Unsaturated Pyroclastic Soils, based on Testing Site Monitoring. Universita Degli Studi di Napoli Federico II (2009)

18. Pagano, L., Picarelli, L., Rianna, G., Urciuoli, G.: A Simple Numerical Procedure for Timely Prediction of Precipitation-Induced Landslides in Unsaturated Pyroclastic Soils. Landslides 7, 273-289 (2010)

19. Borja, R.I., White, J.A., Liu, X., Wu, W.: Factor of Safety in a Partially Saturated Slope Inferred from Hydro-mechanical Continuum Modeling. Internation Journal for Numerical and Analytical Methods in Geomechanics 36, 236-248 (2011) 